\title{
Correction to: 3D printed bone models in oral and craniomaxillofacial surgery: a systematic review
}

Matteo Meglioli ${ }^{1}$, Adrien Naveau ${ }^{2,3,4}$, Guido Maria Macaluso ${ }^{1,5}$ and Sylvain Catros ${ }^{4,6,7^{*}}$

\section{Correction to: 3D Print Med (2020) 6:30}

https://doi.org/10.1186/s41205-020-00082-5

Following publication of the original article [1], the authors identified an error in Fig. 4 which was introduced during typesetting. The correct figure is given below.

The original publication has been corrected. The publisher apologizes to the readers and authors for the inconvenience.

\begin{abstract}
Author details
${ }^{1}$ University Center of DentistryDepartment of Medicine and Surgery, University of Parma, Via Gramsci 14, 43126 Parma, Italy. ${ }^{2}$ Department of Prosthodontics, Dental Science Faculty, University of Bordeaux, 46 rue Léo-Saignat, 33076 Bordeaux, France. ${ }^{3}$ Dental and Periodontal Rehabilitation Unit, Saint Andre Hospital, Bordeaux University Hospital, 46 rue Léo-Saignat, 33076 Bordeaux, France. ${ }^{4}$ Biotis Laboratory, Inserm U1026, University of Bordeaux, 46 rue Léo-Saignat, 33076 Bordeaux, France. ${ }^{5}$ IMEM-CNR, Parco Area delle Scienze 37/A, 43124, Parma, Italy. ${ }^{6}$ Department of Oral Surgery, UFR d'Odontologie, University of Bordeaux, 46 rue Léo-Saignat, 33076 Bordeaux, France. " Service de Chirurgie Orale, CHU de Bordeaux, 46 rue Léo-Saignat, 33076 Bordeaux, France.
\end{abstract}

Published online: 02 December 2020

\section{Reference}

1. Meglioli M, et al. 3D printed bone models in oral and craniomaxillofacial surgery: a systematic review. 3D Print Med. 2020;6:30 https://doi.org/10. 1186/s41205-020-00082-5.

The original article can be found online at https://doi.org/10.1186/s41205020-00082-5.

* Correspondence: sylvain.catros@u-bordeaux.fr

${ }^{4}$ Biotis Laboratory, Inserm U1026, University of Bordeaux, 46 rue Léo-Saignat, 33076 Bordeaux, France

${ }^{6}$ Department of Oral Surgery, UFR d'Odontologie, University of Bordeaux, 46 rue Léo-Saignat, 33076 Bordeaux, France

Full list of author information is available at the end of the article

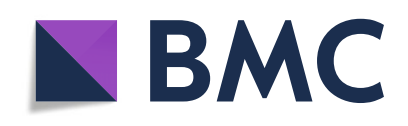

( ) The Author(s). 2020 Open Access This article is licensed under a Creative Commons Attribution 4.0 International License, which permits use, sharing, adaptation, distribution and reproduction in any medium or format, as long as you give appropriate credit to the original author(s) and the source, provide a link to the Creative Commons licence, and indicate if changes were made. The images or other third party material in this article are included in the article's Creative Commons licence, unless indicated otherwise in a credit line to the material. If material is not included in the article's Creative Commons licence and your intended use is not permitted by statutory regulation or exceeds the permitted use, you will need to obtain permission directly from the copyright holder. To view a copy of this licence, visit http://creativecommons.org/licenses/by/4.0/. The Creative Commons Public Domain Dedication waiver (http://creativecommons.org/publicdomain/zero/1.0/) applies to the data made available in this article, unless otherwise stated in a credit line to the data. 
Meglioli et al. 3D Printing in Medicine

(2020) 6:36

Page 2 of 2

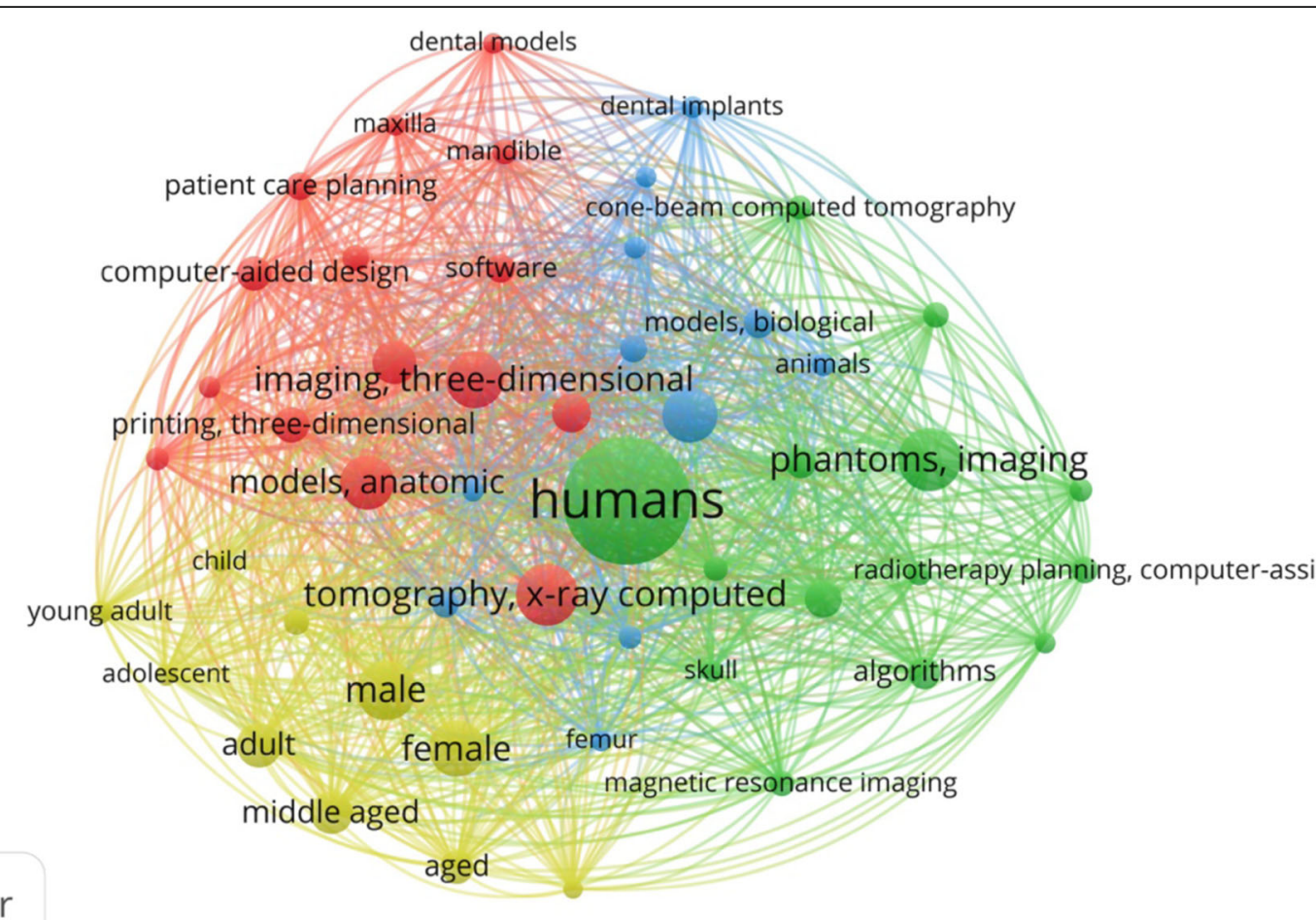

\& VOSviewer

Fig. 4 Mesh keyword co-occurrence networks among the retrieved articles. The size of each node is proportionate to its degree and the thickness of the links represents the tie strength 